\title{
NACOS DO REAL: A PAIXÃO DA ESCRITA EM LÚCIO CARDOSO E CLARICE LISPECTOR
}

RESUMO:

0 presente trabalho consiste em uma leitura das obras de Lúcio Cardoso e Clarice Lispector, a partir do conceito de Real, desenvolvido por Jacques Lacan, como o registro do irrepresentável.

PALAVRAS-CHAVE: real, representação, das Ding, belo.

0 século XX despontou prenhe de novas formas de pensar o homem e 0 mundo, tanto no campo científico quanto na esfera estética. Na virada do milênio, um médico vienense, ao fundar a psicanálise, despontava como um dos focos revolucionários que iriam mudar o pensamento ocidental. Com Freud, apareceu o que era velado e opaco, obrigando o homem a admitir sua divisão, seu lado desconhecido e sua impossibilidade de completude. Ergueu-se o rochedo da castração, que, se por um lado derrubou a onipotência e a certeza do homem, abriu, simultaneamente, nessa zona de impossibilidade, densidade e obscuridade, um espaço inesgotável para a criação. A partir dele e de sua nova visada do homem, movimentos diferentes e contestadores foram se deflagrando no campo do pensar e notadamente no mundo da representação artística, havendo um grande intercâmbio de influências entre a psicanálise e as artes. Esse intercâmbio se intensificou nos anos 20 e 30 entre Lacan, responsável por uma importante e extensa releitura de Freud, e artistas, como os surrealistas e os dadaístas.

Já no final do século XIX, a representação pictória havia sofrido uma mudança com o movimento dos impressionistas. Esses artistas, numa primeira exposição coletiva na França, em 1874, revelaram pinceladas que pareceram confusas e chocantes

|* Mestre em Letras: Estudos Literários (Área de concentração: Literatura Brasileira), 2000. 


\section{EM TESE}

Belo Horizonte, v. 5, p. I-305, dez. 2002

para os tradicionalistas. A representação perdia seus contornos definidos, que se desfaziam, ficavam borrados para privilegiar a luz e seus efeitos. Além disso, com o movimento cubista, a representação sofreu novos ataques: os planos passavam a ser quebrados e os objetos fragmentados e apresentados de vários pontos de vista, simul taneamente.

No Brasil, a revolução nas artes tem como marco a Semana de Arte Moderna, em 1922, uma amostra de explosão e renovação das formas em todos os campos artísticos. Depois, tendo como referência o ano de 1956, alguns acontecimentos literários romperam mais uma vez com os movimentos anteriores e reformularam os valores estéticos. Dentre esses acontecimentos, destacam-se: o surgimento da poesia concreta; e o aparecimento de romances como Grande sertão: veredas, de João Guimarães Rosa, este último, criador de uma nova linguagem literária.

Clarice Lispector surge nesse panorama como um dos nomes que fazem a inscrição de um novo paradigma estético na literatura brasileira. Já Lúcio Cardoso costuma não ser muito citado nas histórias literárias canônicas. Apesar de já ter, na ocasião, vários livros publicados que traziam uma nova estética, continuou circulando na marginalidade do cânone.

Todos esses acontecimentos revelam, em seu cerne, uma crise da forma de representar. 0 que chamamos hoje de "crise da representação" é o descrédito que foi se espalhando entre pensadores, artistas e escritores de que se pudesse ter uma representação que fosse cópia fiel de uma realidade, ou, mais ainda, a descrença numa realidade a priori a ser representada, pois passou-se a entender que se cria a realidade com as palavras e que se tem várias formas de apresentá-la e de construi-1a. Fracassando a representação total, bem delineada e bem trabalhada, respeitosa das formas e sintaxes tradicionais, mudou-se também o conceito de belo, que passou a ser diverso da beleza padronizada pelas boas formas, da vaidade, do campo dos bens, dos excessos e dos adornos, chegando a se aproximar do próprio horror.

Psicanaliticamente, poderíamos dizer que o belo se afastou do campo do imaginário para chegar ao campo do Real. É o que se pode depreender do ensino de Lacan, que dedicou um longo tempo, em seu 0 Seminário - Livro 7, para o exame das relações da arte com o campo do Real. Referindo-se inicialmente à arte primitiva, 
gravada no interior das cavernas, Lacan, fascinado por essa inscrição nas paredes de um vazio, explica que são imagens que têm um caráter de para-além do sagrado.

Lacan designa esse "para-além" por meio do termo das Ding. 0 para-além de das Ding é um para-além do princípio de prazer, do âmbito da afetividade, do sujeito submetido à mediação significante, sendo algo de muito mais essencial. Freud encontra o campo de das Ding quando percebe que, além do princípio de prazer, a vida pode preferir a morte. Nesse momento, Freud "lida com as potências da vida na medida em que desembocam nas da morte, ele lida diretamente com as potências que emanam do conhecimento do bem e do mal". (Lacan, 1995: 133).

Nas palavras de Lacan, das Ding está "no âmago da tramóia humana, ou seja, (...) no meio da floresta dos desejos, e dos compromissos que os tais desejos estabelecem com uma certa realidade (...)". (Lacan, 1995: 132). No centro de todo o círculo das representações sociais e culturais, da linguagem e da significação, reside o núcleo do mais arcaico, do mais primitivo, de das Ding, considerado pelos kleinianos como o corpo mítico da mãe. Objeto absoluto, inatingível, impossível de dizer e de delinear, das Ding é um marco mítico, anterior a qualquer simbólico, mas onde se apóia o aparelho psíquico. É o impensável da origem.

Tendo como tradução $A$ Coisa, das Ding não é, entretanto, a coisa a que o homem se refere e que é criada com suas palavras. Há outra coisa em das Ding: é o elemento originalmente isolado pelo sujeito como sendo, por sua natureza, estranho, e a que chamaremos de o fora-do-significado. A Coisa é um pólo excluído do aparelho psíquico em torno do qual giram os movimentos do desejo e do pensamento, as percepções e representações. A barreira que separa esse campo de das Ding é a última boa forma, também chamada da barreira do belo. Ultrapassá-la é, na opinião de Lacan, ultrajar.

Enquanto, para Freud, a sublimação tinha conotação moral - satisfazer a pulsão através de objetos socialmente aceitos - para Lacan, a sublimação é cometer o ultraje, atravessar o círculo encantado e elevar o objeto à dignidade da Coisa.

A sublimação implica a maleabilidade da arte para entrar nessa zona de perigo de das Ding e transformar esse vazio em alguma coisa que, ao invés de tamponá-10, vai fazê-10 aparecer. 0 principal na sublimação é a criação no vazio, 


\section{EM TESE}

Belo Horizonte, v. 5, p. I-305, dez. 2002

é abrir o vazio, apagando o campo das significações, atravessando o campo dos bens, dos objetos de troca, apagando o campo da materialidade. As formas do objeto se volatilizam para deixar surgir o objeto inacessível e, assim, através de alguma forma, engendrar o vazio do real, a dignidade da Coisa.

A literatura de Clarice realiza essa ultrapassagem, não temendo se sustentar nessa barreira entre o belo e o horror de das Ding. Em seu livro A Paixão segundo G.H., Clarice comete, de fato, o ultraje, ultrapassando a barreira do belo, para chegar ao "não humano", que, como ela explica, não significa "desumano", mas, pelo contrário, é a "matéria viva se manifestando diretamente, desconhecendo palavra, ultrapassando o pensar que é sempre grotesco". (Lispector, 1996: 110).

Podemos perceber que ela caminha em sua escrita no mesmo sentido que Lacan aponta como sendo o da arte: a criação ex-nihilo. A personagem G.H., ao se deparar com uma barata emergindo da porta de um armário, resolve, sem pudor, entregar-se ao que era o mal e, num só golpe, fechar a porta do armário sobre o corpo da barata. Encarando a barata esmagada, passa por reflexões que, em suas palavras, a levavam em derrocada difícil fazendo abrirem-se dentro dela passagens duras e estreitas. E assim vai atravessando limites: (...) "estou indo para o inferno de vida crua". (Lispector, 1996: 40).

Ao ver sair, lentamente, da barata esmagada, como de uma bisnaga, sua matéria interior, a narradora pensa que a matéria da barata era o seu de dentro, a matéria grossa, esbranquiçada, entendendo que, a seu próprio respeito, o que havia de estrangeiro dentro dela estava, pela primeira vez, fora dela e ao seu alcance, "incompreensivel, mas ao seu alcance". (Lispector, 1996: 42). Sente ainda que dera um passo mal-assombrado e irremediável e que dissera adeus à beleza do mundo: "a beleza, aquela nova ausência de beleza que nada tinha daquilo que eu antes costumava chamar de beleza, me horrorizava". (Lispector, 1996: 63).

Dando adeus à beleza como a um engodo suave, que enfeitava a coisa para poder tolerar-1he o núcleo, G.H. admite a dificuldade de se chegar ao primitivo, ao incompreensível, o inexpressivo, seja pelo perigo que isso acarreta, seja pelo fato de estarmos mergulhados na linguagem. Como tocar na mudez da coisa, tendo, para isso, exatamente as palavras? 
Existe uma coisa que é mais ampla, mais surda, mais funda, menos boa, menos ruim, menos bonita. Embora também essa coisa corra o perigo de, em nossas mãos grossas, vir a se transformar em "pureza", nossas mãos que são grossas e cheias de palavras. (Lispector, 1996: 101).

Para não correr o risco de perder "essa coisa" no meio das palavras, Clarice recorre ao ato: faz G.H. botar na boca a massa branca da barata. Atravessando uma sensação de morte, coberta de suor, nauseada, num momento de vertigem, G.H. acredita ter cumprido o gesto. Primeiramente confusa, não sabendo o que acontecera, é balançada pela lembrança quando todo seu corpo grita: "Crispei minhas unhas na parede: eu sentia agora o nojento na minha boca, e então comecei a cuspir, a cuspir furiosamente aquele gosto de coisa alguma, gosto de um nada". (Lispector, 1996: 107). De uma maneira chocante, Clarice atravessa a fronteira do compreensível, do suportável, para ir ao encontro da coisa inominável, do centro irrespirável.

Lacan observa que

a verdadeira barreira que detém o sujeito diante do campo inominável do desejo radical uma vez que é o campo da destruição absoluta, da destruição para além da putrefação, é o fenômeno estético propriamente dito, uma vez que é identificável com a experiência do belo - o belo em seu brilho resplandecente, esse belo do qual disseram que é o esplendor da verdade. É evidentemente por o verdadeiro não ser muito bonito de se ver, que o belo é, senão seu esplendor, pelo menos sua cobertura. (Lacan 1995: 265).

Assim, Lacan considera que o belo, ao mesmo tempo que nos detém, indicanos em que sentido se encontra o campo da destruição e que, nesses termos, o belo está mais perto do mal do que do bem.

0 fenômeno do belo é definido, ainda, de outra forma por Lacan, como sendo o limite da segunda morte, um lugar "entre dois": a primeira morte é a morte biológica, inevitável e real, e a segunda morte, a morte vivida de maneira antecipada, aquela que invade o domínio da vida. Esse lugar "entre" é um lugar onde se pode passar pouco tempo, é o que está para além de um certo limite que não deve ser visto, um findalinha, uma zona limite entre a vida e a morte. Constitui-se em um ponto de anamorfose, um lampejo de imagem que se deforma e se decompõe. 0 belo reside nesses confins.

Em outra tentativa de definir o belo, Lacan descreve sua função como sendo a de nos indicar "o lugar da relação do homem com sua própria morte e de nos indicá-los somente num resplandecimento". (Lacan, 1995: 354). 


\section{EM TESE}

Belo Horizonte, v. 5, p. I-305, dez. 2002

Esse 1 imite pode ser bem representado na forma humana, no próprio corpo, no ponto em que ele deixa de ser um corpo erogeneizado, falado, imaginário, para ser carne, quando desencadeado do imaginário e do simbólico, é afetado pelo Real.

0 belo de Lúcio Cardoso é exatamente o belo ideal de Lacan, situado nesse ponto entre a vida e a morte, na exposição do corpo-cadáver, do real do corpo, o "naco de carne", a carcaça humana. Para ele, conscientemente, o belo se situa no mesmo entre-lugar teorizado por Lacan, como podemos ler em seu Diário I:

Tudo o que é belo, só deve ser útil para fazer crescer nossa impressão de intranquilidade. A beleza é o supremo espasmo, a angústia máxima, o sentimento maior de furor ante a fragilidade e a possibilidade de destruição de tudo. E é assim, sob o terror, que o homem se realiza integralmente. Estamos nus, integrais em toda a estranheza de nosso trágico destino, quando sentimos 0 chão faltar sob nossos pés. (Cardoso, [s.d.]: 48).

Em seu livro A crônica da casa assassinada, várias cenas são construídas entre a vida e a morte, a paixão da carne e a destruição do corpo, envolvendo a paixão de André e Nina em seu leito de morte:

0 que vinha nele erguia-se com o impulso de uma seiva acendendo ao longo de um caule - só que a ramaria se achava morta, e nenhuma flor brotava mais desta paisagem em despedida (...). Não sua alma, mas seus lábios apenas, impregnados dessa saliva grossa que era como o último resíduo da paixão terrena e do esforço da carne, tentavam reanimar o delírio da vida passada (...) eu tinha consciência de que já nos achávamos diante da cena final, em um soluço seco, irrefreável, atravessava-me a garganta (...). (Cardoso, [s.d.]: 16).

Há, no romance, uma mistura entre corpo em decomposição e corpo desejante, entre objetos terminais sombrios (ampolas, frascos de remédios) e objetos iluminados pelo desejo, na fronteira entre a vida e a morte. Ainda há vida, há desejo, ainda existe beleza, mas a mancha da decomposição vai se impondo: "(...) desatinado, colei meus lábios ao seu pobre braço murcho e suguei-o, procurando reter a frágil palpitação, até que nele se alargou uma nódoa escura". (Cardoso, [s.d.]: 289). Na beirada da morte, no ponto de desaparecimento, está o corpo de Nina, marcando o lugar da escrita de Lúcio numa fina lâmina que separa o desejo da decomposição e da morte.

Outro caminho que Lúcio toma para chegar ao Real é o do gesto cruel e radical do crime. Em 0 viajante, ele ultrapassa a barreira de algo mitificado e 
sacralizado em nossa cultura: o amor materno. Donana de Lara, para se ver livre do filho Zeca, doente, paralítico e mudo, leva-o até a beirada de um morro na região do matadouro da cidade e, em cima do barranco que descia em corcovas bruscas até o leito quase seco de um riacho onde um bezerro apodrecia com as vísceras de fora, cercado de urubus, ela empurra a cadeira com o menino que levava uma rosa na mão:

0 movimento da cadeira descendo, ou o tremor do corpo de Zeca, o que quer que fosse, o certo é que a rosa se desfolhou. Ela fechou os olhos, escutando 0 barulho das rodas nas pedras. A cadeira bateu finalmente numa pedra, desviouse, rodou um pouco mais, atingiu uma rampa mais ingreme, acelerou a queda e, finalmente, chocando-se violentamente contra outra pedra, virou pra cima, atirando o corpo de Zeca - um, dois, três trambolhões - rolou em nova rampa esfrangalhando, chocou-se contra um último obstáculo e afinal foi tombar, inerte, ensanguentado, a poucos metros da rês apodrecida. (Cardoso, 1973: 14).

Lúcio comete o ultraje a que se refere Lacan, ao romper a barreira do bem, da moral, do santificado, e ultrapassar a barreira do belo, no corpo esfrangalhado.

No mesmo livro, outro crime acontece. Mestre Juca, construtor de caixões, se enamora de Sinhá, moça ingênua, de 19 anos, e, ao perceber a impossibilidade de realizar seu desejo, cerca-a num pontilhão, para matá-1a. Mestre Juca ergue o machado:

(...) - dura arma do crime em sua mão de criminoso - e ela desceu no espaço, inocente, desenhando o seu primeiro golpe. 0 golpe não importava, era apenas um golpe, com essa bestialidade e essa certeza que desencadeiam os gestos do crime (...). Quando mestre Juca vibrou o terceiro golpe, Sinhá já se achava de joelhos - e desta vez ela sentiu a dor (...) - e então ela foi dor, dor única $(. .$.$) - e curvou-se, ainda de joelhos, mas já sentindo caminhar pelo$ seu ser o escuro da morte. Mas viva, a dor ainda existia - era música. Como uma orquestra que de repente movimentasse os seus metais clássicos, o que era dor, e significava música, de repente se fez sentir - dentro do seu ser já semidespedaçado, uma valsa antiga (...) - começou o seu percurso - e esta valsa era a morte (...).

Respingada de sangue, naquele escuro sem identidade, ela sentiu o vermelho como um gosto na boca - (...) Sinhá nada sabia, Sinhá tinha 19 anos, e a imagem de sua morte, tinha a imagem do amor - era um tié-sangue. Primeiro ela os viu aos respingos, como um bando de pássaros que revoassem em torno dela. Eram pássaros e pássaros - e eram todos vermelhos, como aquele que um dia, palpitante, ela designara junto ao bambual. Eram tantos pássaros quanto as gotas de sangue que a cobriam.

E tudo isso voava e revoava em silêncio, pássaros fechados e fluidos, como duras notas de música feitas desse som especial de que se faz certa música de cor e de espuma. (Cardoso, 1973: 172-174). 


\section{EMTESE}

Belo Horizonte, v. 5, p. I-305, dez. 2002

Quando Lacan observa, n'O Seminário - livro 7, que o belo está mais perto do mal do que do bem e que ele espera que isso não espante muito seus ouvintes, poderia ter Lúcio Cardoso como exemplo. Esses fragmentos mostram exatamente isso. Lúcio não retira o véu da beleza: faz ver através dele o que pode haver de mais cruel, mais próximo de um Real da morte.

Uma valsa antiga, um bando de pássaros vermelhos são também a morte, 0 sangue, o corpo ferido. 0 mais belo, o mais suave é também o ponto mais radical do mal e do horror. A valsa e os pássaros não são metáforas, são uma e a mesma coisa que a morte, borrando e desfazendo a barreira que separa o belo do Real.

Lúcio e Clarice escrevem com as últimas letras, no último anteparo, conseguindo, com suas palavras, chegar ao duro silêncio da morte e à bruta consistência da matéria-coisa crua, criando lampejos de rara beleza, singularizando-se como escritores na literatura brasileira e mostrando que, aquilo que a psicanálise trabalha, a literatura escreve.

ABSTRACT :

A Study of Lúcio Cardoso's and Clarice Lispector's works through a reading based on Lacan's concept of the Real as a register of what cannot be represented.

KEY WORDS: Real, representation, das Ding, beauty.

REFERÊNCIAS BIBLIOGRÁFICAS

CARDOSO, Lúcio. A crônica da casa assassinada. Rio de Janeiro: Ediouro, [s.d.]. - Diário I. Rio de Janeiro: Elos, [s.d.]. - Dias perdidos. Rio de Janeiro: José 01ympio, 1943. - O viajante. Rio de Janeiro: José 01 ympio, 1973.

LACAN, Jacques. O seminário - livro 7: a ética da psicanálise. Rio de Janeiro: Jorge Zahar, 1995.

LISPECTOR, Clarice. A paixão segundo G.H. Francia: Scipione, 1996. 